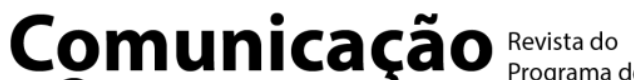



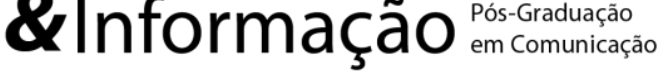

\section{Escavações de Audiovisualidades em Narrativas Site-specific}

\author{
Excavations of Audiovisualities in Site-specific Narratives \\ Excavaciónes de Audiovisualidades en Narrativas Site-specific
}

\author{
Tiago Lopes ${ }^{l}$ \\ Gustavo Fischer ${ }^{2}$
}

\begin{abstract}
Resumo:
Propõe uma reflexão a respeito das audiovisualidades - tomadas enquanto qualidades audiovisuais que se atualizam em formatos diversos em nossa tecnocultura - presentes em duas experiências narrativas, as quais foram projetadas para serem acessadas e acionadas em conexão com determinadas localidades (site-specific): os projetos artísticos 34N118W (2003) e A machine to see with (2010). Metodologicamente, apoia-se na perspectiva da arqueologia da mídia, adotada enquanto visada que propõe a realização de escavações materiais e memoriais com vistas à autenticação de devires tecnoculturais nos objetos pesquisados. Neste movimento, são propostas quatro camadas de audiovisualidades narrativas: caminhantes, urbanas, locativas e guiadas. Em articulação, estas camadas dão a ver estéticas de conectividades híbridas que seguem sustentando lógicas de desafio ao estatuto das imagens técnicas.
\end{abstract}

Palavras-chave: Audiovisualidades. Escavação. Narrativas site-specific. Arqueologia da mídia. Mídias locativas.

\begin{abstract}
:
Proposes a discussion about audiovisualities - understood as audiovisual qualities that are updated in different formats in our technoculture - present in two narratives which were designed to be accessed and activated in connection with certain locations (site-specific): the projects 34N118W (2003) and A machine to see with (2010). Methodologically, it is based on the perspective of media archeology understood as an angle that proposes both excavations of materials and memories for the authentication of technocultural becomings that can be perceived in these works. In this movement, four layers of narrative audiovisualities are proposed: walkers, urban, locative and guided. In articulation, these layers show aesthetics of hybrid connectivities that continue to support logics of challenge to the status of technical images.
\end{abstract}

Keywords: Audiovisualities. Excavation. Site-specific narratives. Media archeology. Locative media.

\section{Resumen:}

Propone una discusión sobre las audiovisualidades - tomadas como cualidades audiovisuales que se actualizan en diferentes formatos en nuestra tecnocultura - presentes en dos narrativas que fueron diseñadas para ser accedidas y activadas en relación con determinadas localizaciones (site-specific): los proyectos 34N118W (2003) y A machine to see with (2010). Metodológicamente, se sustenta en la perspectiva de la arqueología de los medios, adoptada con el objetivo de proponer la realización de

1 Universidade do Vale do Rio dos Sinos (UNISINOS), São Leopoldo, Rio Grande do Sul, Brasil, tricciardi@unisinos.br.

2 Universidade do Vale do Rio dos Sinos (UNISINOS), São Leopoldo, Rio Grande do Sul, Brasil, gfischer@unisinos.br. 
excavaciones materiales y memoriales con miras a autenticar desarrollos tecnoculturales en los objetos investigados. En este movimiento se proponen cuatro capas de audiovisualidades narrativas: caminantes, urbanas, locativas y guiadas. En articulación, estas capas muestran una estética de conectividades híbridas que continúan apoyando lógicas de desafío al estado de las imágenes técnicas.

Palabras clave: Audiovisualidades. Excavación. Narrativas site-specific. Arqueología de los medios. Medios locativos.

\section{INTRODUÇÃO}

Frequentemente, diversos autores atribuem ao Cinema, enquanto meio de comunicação matricial da cultura audiovisual, uma qualidade de modelo de pensamento da imagem tecnológica, conferindo-lhe importante papel de força constituidora de imaginários nas sociedades contemporâneas. Para Philippe Dubois (2004, p. 25), "queiramos ou não, nosso pensamento da imagem é hoje um pensamento "cinematográfico"”. Aproximando esta reflexão das materialidades midiáticas digitais, Lev Manovich (2001) encontra no cinematismo uma qualidade em devir que se explicita em diversas iniciativas das chamadas mídias digitais da virada do século XXI, tanto em obras de cunho mais experimental sobretudo de Internet Art e de outras variantes das artes digitais - quanto em jogos eletrônicos (games).

No entanto, ainda que a tela de projeção cinematográfica determine, simbolicamente, o marco referencial que fundamenta o pensamento sobre a imagem em movimento, ao longo do último século outros tantos tipos de "telas" vieram se juntar a ela - dos monitores de vídeo (dos aparelhos televisivos e, sobretudo, dos computadores pessoais) às interfaces dos dispositivos móveis, o atual estatuto das imagens técnicas desafia-nos a compreender suas lógicas de produção e consumo, de controle e liberdade, e, também, de éticas e estéticas tecnológicas (SANTAELLA, 2007), as quais indicam modos sui generis de produção de subjetividade aportados por novas ambiências multissensoriais, nas quais os atos de "ver" ou "assistir" imagens demandam menos o uso da visão do que de outros sentidos do corpo. Neste trabalho, interessa-nos abordar as narratividades emergentes em práticas artísticas que intencionam produzir, por meio do uso de recursos tecnológicos diversos, experiências projetadas para ocorrerem em lugares específicos (site-specific).

Tendo consciência da variedade de propostas que fazem uso de tecnologias digitais principalmente mediante o emprego de mídias móveis e locativas - para promoverem experiências com finalidades artísticas, lúdicas e criativas baseadas em localidades 
específicas $^{3}$, interessa-nos restringir nossas observações a alguns projetos que se diferenciam pelo uso de elementos sonoros como principal meio de vinculação entre a experiência narrativa e o ambiente em que as obras/performances acontecem. Neste sentido, tomaremos como locus de exploração analítica os projetos artísticos 34N118W (2003) e A machine to see with (2010).

O primeiro, $34 N 118 W^{4}$ (2003), oferece aos seus participantes experiências de exploração do ambiente urbano através do acesso a arquivos sonoros que dão a ver rastros do passado: acontecimentos históricos, lembranças pessoais, mensagens deixadas a gerações futuras. O segundo, A machine to see with $^{5}$ (2010), desenvolvido pelo grupo de artistas Blast Theory, apresenta uma experiência narrativa que se estende pelas ruas da cidade, por quase uma hora, totalmente mediada por estímulos sonoros.

Além da ênfase sobre as sonoridades, uma característica em comum destes projetos é a incorporação de eventuais acontecimentos relacionados ao deslocamento espacial dos sujeitos participantes, como, por exemplo, as possíveis interações com objetos e demais elementos que integram a paisagem dos locais em que as obras/performances acontecem. A assimilação destes elementos oferece, por um lado, uma ampla gama de possibilidades estéticas e narrativas, que excede a simples remediação (BOLTER; GRUSIN, 2000) de formatos, linguagens e práticas audiovisuais já consagrados por outros meios (notadamente pelo cinema e pela televisão); por outro lado, evocam e, portanto, atualizam distintas ordens de experiência sensorial, as quais situam-se numa espécie de periferia da história da cultura visual.

À vista disto, nossa abordagem insere-se, metodologicamente, em uma matriz de pensamento que evita inscrever tais práticas em perspectivas evolucionistas ou teleológicas, pelo contrário, demarca a importância de compreender esta noção de periferia como oportunidade de redimir tanto as materialidades envolvidas como suas condições de existência, seguidamente soterradas pelas lógicas da obsolescência programada e da celebração de formatos e narrativas "vencedores" por alcançarem maior audiência, número de downloads, curtidas ou outras sinalizações de massificação. Assim, entendemos o processo de resgate e problematização destes objetos nesta direção, como uma iniciativa inspirada na arqueologia das mídias, campo de estudos um tanto heterogêneo em suas abordagens, mas

3 Diversos autores buscaram classificar as diferentes modalidades de exploração criativa com dispositivos móveis: projetos anotativos e fenomenológicos (TUTERS; VARNELIS, 2006); mapeamentos digitais, anotações urbanas eletrônicas, jogos locativos móveis e realidade aumentada móvel (LEMOS, 2007); narrativas terrestres (EPSTEIN, 2009); narrativas móveis (CORNELIO, 2010).

https://34n118w.net/34N/.

5 A MACHINE TO SEE WITH. Blast Theory, [S. l.], 2010. Disponível em:

https://www.blasttheory.co.uk/projects/a-machine-to-see-with/. Acesso em: 10 out. 2020. 
suficientemente demarcador da potência investigativa que "escava" - enquanto acionamento básico do agir arqueológico - tanto dimensões materiais (a descrição e dissecação de artefatos, imagens, aparelhos, documentos, etc.) quanto memoriais (linguagens, mecânicas, contextos de uso, sentidos tecnoculturais) dos objetos. Camadas podem ser entendidas como estratificáveis e arqueologizáveis (dissecáveis, rastreáveis, autenticáveis) e nos permitem ver o que nelas dura de outras mídias, formas culturais, práticas, materialidades, entre outros aspectos.

Huhtamo e Parikka (2011) descrevem a arqueologia da mídia como uma prática, cujos estudos enfatizam aspectos negligenciados ou mal-representados, indo ao encontro daquilo que Felinto (2011) lembra que a cultura da mídia, costumeiramente, chama de "ruído". As "escavações" de evidências suprimidas, tanto do passado quanto do presente da história da mídia, tentam trazer à tona elementos ruidosos e ignorados para que eles interajam entre si e iluminem mecanismos ideológicos por detrás destes fenômenos da cultura da mídia.

Ainda que em se tratando de iniciativas que surgem, cronologicamente, na primeira década deste século, a ideia de uma angulação mídio-arqueológica sustenta-se na medida em que vamos ao encontro do que Lev Manovich entende ser necessário quando reivindica uma “teoria do presente", em sua obra seminal Language of new media (2001), ao expressar seu ambicioso projeto de testemunhar a emergência do computador como metameio:

Em contraste com cem anos atrás, quando o cinema estava surgindo, temos plena consciência do significado dessa nova revolução da mídia. Ainda assim, temo que os futuros teóricos e historiadores da mídia computacional não ficarão com muito mais do que os equivalentes das reportagens de jornais e programas de filme das primeiras décadas do cinema. (MANOVICH, 2001, p. 6, tradução nossa) ${ }^{6}$.

Nosso percurso ${ }^{7}$ pelas duas iniciativas ocorrerá mediante um ingresso descritivo breve, mas que dá vazão à autenticação de determinadas camadas memoriais que ali se inscrevem enquanto devires de uma tecnocultura audiovisual. É importante, então, assinalar o entendimento do conceito de audiovisualidades como as qualidades audiovisuais que se atualizam em formatos - com suas linguagens, técnicas e estéticas - que não ficam irredutíveis a uma mídia mais recorrente ou convencional (televisão ou cinema, por

6 "In contrast to a hundred years ago, when cinema was coming into being, we are fully aware of the significance of this new media revolution. Yet I am afraid that future theorists and historians of computer media will be left with not much more than the equivalents of the newspaper reports and film programs from cinema's first decades."

7 Ressalta-se que as discussões aqui elencadas, a partir destas duas iniciativas destacadas, estão vinculadas à pesquisa mais ampla de doutorado de Lopes (2014). 
exemplo) $)^{8}$

\section{ESCAVANDO OS OBJETOS}

O projeto 34 North 118 West - também conhecido como $34 N 118 \mathrm{~W}$ - é um trabalho de arte desenvolvido por Jeff Knowlton, Naomi Spellman e Jeremy Hight, em que o usuário percorre um trajeto urbano em Los Angeles e, conforme caminha, acessa, através de um dispositivo móvel com a aplicação do projeto instalada, informações de áudio que apresentam micronarrativas (em sua maioria depoimentos de mulheres e homens, habitantes da região) que contam a história daquele local, que, em seu passado, foi um importante distrito industrial da cidade.

Figura 1 - Imagem do projeto 34 North 118 West

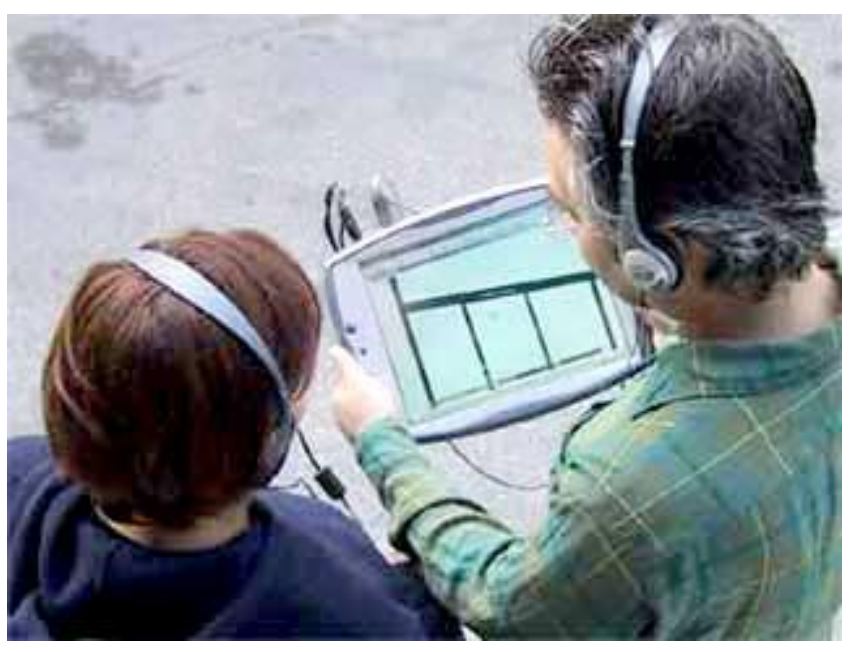

Fonte: 34N118W (2003).

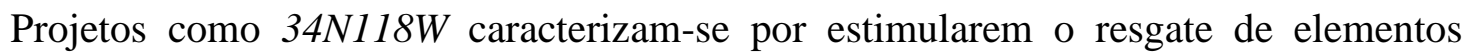
narrativos do passado através de fragmentos de áudio dispersos pela cidade. Ao incentivarem que seus participantes escutem relatos de acontecimentos ocorridos nos locais em que os arquivos sonoros são acessados, promovem diferentes modalidades de atualização tempoespacial; deste modo, provocam deslocamentos de sentido sobre os lugares em que a experiência narrativa toma forma, produzindo enunciações sobre os territórios, as quais thes atribuem qualidades memoriais (JENKINS, 2004) e arqueológicas (HIGHT, 2006).

Em relação a como os participantes acessam e experimentam as histórias narradas, por meio de arquivos de áudio, os conteúdos não seguem uma narrativa modular sequencial, isto

8 Sobre as reflexões que ensejam o conceito de audiovisualidades, recomenda-se a consulta às pesquisas de Suzana Kilpp (2006). 
é, não apresentam-se "amarrados" uns aos outros, cabendo ao usuário acessá-los na ordem que preferir - diferem-se, conforme veremos, da proposta de estrutura narrativa oferecida em A machine to see with (2010).

Figura 2 - Imagem do projeto A machine to see with

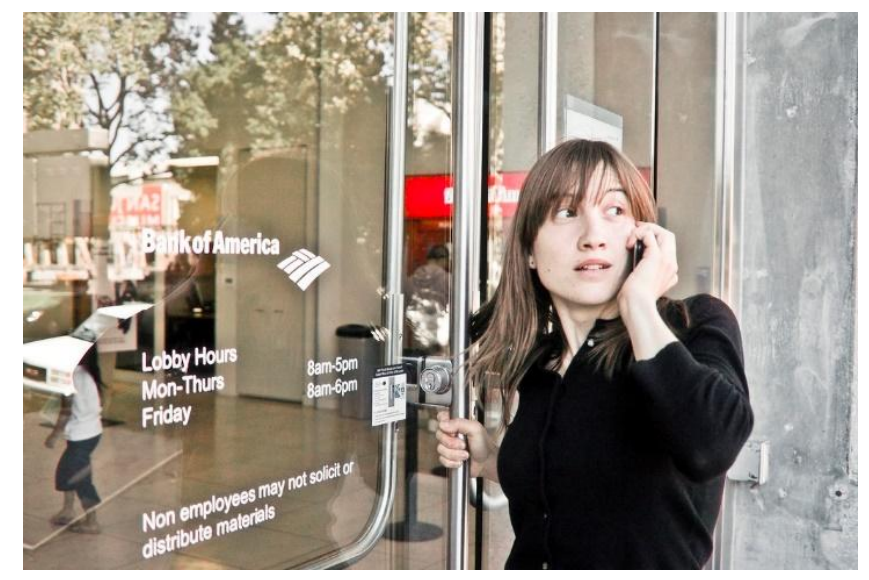

Fonte: A machine to see with (2003) ${ }^{9}$.

Outro projeto artístico com mídias móveis em que a dimensão sonora exerce importante mediação entre o corpo e o espaço é A machine to see with, desenvolvido pelo grupo de artistas britânicos Blast Theory. Misturando elementos de performance e teatro, $A$ machine to see with apresenta uma experiência de narrativa orientada por estímulos sonoros gerados a partir de ligações telefônicas.

A peça inicia da seguinte maneira: os participantes se cadastram para participar de um "filme" no qual, supostamente, devem atuar como protagonistas e cujo enredo gira em torno do planejamento e da realização de um assalto a banco. Via ligações de telefone celular, os participantes interagem com uma "voz" que solicita que tarefas sejam realizadas e decisões sejam tomadas a todo momento. Enquanto isto, eles se deslocam a pé e exploram regiões da cidade conforme instruções vão sendo transmitidas durante as ligações telefônicas. A jornada avança pelas ruas da cidade como num filme de ação. As referências aos gêneros policiais são claras: o convite ao assalto, o planejamento, a preparação, as ações clandestinas, a dissimulação, os picos de tensão.

Desta maneira, poderíamos dizer que, em A machine to see with, códigos cinematográficos de filmes do gênero policial são mapeados e traduzidos para um contexto de performance urbana no qual o corpo do usuário do dispositivo móvel exerce um papel central,

9 Disponível em: https://farm5.static.flickr.com/4111/4994228605 f91fd266e5 b.jpg. Acesso em: 10 out. 2020. 
através de um conjunto de instruções que geram uma espécie de passo-a-passo a ser executado pelo participante, conferindo a esta experiência uma qualidade "algorítmica".

Após este percurso escavatório inicial, nos voltamos para uma problematização mais aprofundada, buscando propor a presença de camadas de audiovisualidades - caminhantes, urbanas, locativas, guiadas - as quais atualizam narratividades sonoras em lugares específicos (site-specific).

\section{AUDIOVISUALIDADES CAMINHANTES}

Publicado em 1989, o artigo The Walkman and the primary world of the senses, de Rainer Schönhammer (1989), apresenta um estudo sobre o hábito de escutar música em aparelhos portáteis do tipo Walkman, que poderíamos entender como um artefato precursor de todos os players portáteis de música que conhecemos hoje em dia. ${ }^{10}$

Apoiado no pensamento do fenomenologista alemão Erwin Straus, Schönhammer questionava sobre o que levava as pessoas a escutarem música neste tipo de aparelho e quais seriam as sensações físicas e cognitivas vivenciadas durante a atividade. Utilizando-se de métodos experimentais de coleta de dados, o pesquisador pediu para que voluntários percorressem determinadas distâncias repetidas vezes, alternando entre executar a tarefa com e sem o uso do Walkman. Variações desta dinâmica também foram empregadas: em uma delas Schönhammer pedia para que os voluntários registrassem sua voz com um gravador enquanto caminhavam; em outra, pedia para que tirassem fotos durante o trajeto. Ao final, os voluntários eram solicitados a relatar suas impressões sobre as diferentes experiências.

O ponto central das conclusões de Schönhammer (1989) é que as propriedades qualitativas do som afetavam de modo bastante peculiar a percepção espaço-temporal de usuários de Walkman. Para ele, tal sentimento de estranhamento seria decorrente não propriamente da eliminação dos sons do ambiente, ocasionada pelo uso dos fones de ouvido, mas devido à substituição dos sons "naturais" pela música do aparelho. No depoimento de um dos voluntários que participaram da referida pesquisa é particularmente notável a intensidade com que o efeito da música incidia sobre seu aparato sensorial e, por consequência, como isto afetava sua percepção do mundo. Quando estava "plugado" aos fones de ouvido, dizia ele,

O mundo parece magnífico, muito mais colorido, muito mais variado, muito mais livre. É como um panorama, como um filme, como um filme com uma

10 Ainda que o conhecido modelo iPod, fabricado pela Apple, continue sendo comercializado, atualmente, as principais características dos antigos players de áudio comparecem integradas às funcionalidades de outros tipos de dispositivos móveis, como os telefones celulares. 
narrativa. A realidade muda. A gente sente como se estivesse fora da realidade. No entanto, ainda estamos na realidade. Sentimos o tempo e o espaço muito mais calmamente. Minha percepção se torna mais apurada. $\mathrm{O}$ espaço se torna mais interessante também. Porque eu vejo o mundo como uma peça de teatro, eu acho, o espaço é o palco onde se pode mover livremente, em particular onde se pode fazer música. ${ }^{11}$ (SCHÖNHAMMER, 1989, p. 132, tradução nossa).

Para Schönhammer (1989), este depoimento reflete um importante aspecto da alteração que se efetua na relação do sujeito com o mundo na experiência de uso do Walkman. O trajeto percorrido, quando sob a influência da música, parece perder a familiaridade, torna-se estranho: "é como se estivéssemos fora da realidade", diz o depoente num primeiro momento, para, em seguida, complementar que, ainda assim, se sentia "na realidade". Nos depoimentos dos voluntários da pesquisa, esta dificuldade de verbalização é particularmente notável e o uso de metáforas e analogias a outras experiências também únicas e singulares, porém, presumivelmente familiares a outras pessoas, torna-se uma estratégia recorrente.

Outro voluntário dos testes coordenados por Schönhammer (1989) afirmava ter a sensação de que, às vezes, os acontecimentos do mundo ao seu redor comportavam-se em sincronia com a música que tocava no seu Walkman - em certa altura do percurso, o depoente viu alguém caminhando apressado pela rua, carregando uma pasta de executivo e, neste exato momento, os Beatles cantavam a canção Let it be no seu Walkman, gerando um efeito de sincronização entre a imagem e o som. Quando este tipo de sintonia acontecia, a sensação, segundo o seu relato, era como se a música, de alguma maneira, fosse a responsável por disparar e, de certa forma, conduzir determinados eventos presenciados.

Ao refletirmos sobre a estética das narratividades site-specific, percebemos que uma das características mais importantes dos objetos analisados é, justamente, a utilização do potencial oferecido por tais tecnologias para sincronizar e disparar diferentes ordens de eventos durante o trajeto de um sujeito que se desloca pelo espaço. Tal como observado através do relato de um dos voluntários da pesquisa do professor Schönhammer, que sentia que os eventos presenciados ao longo do percurso estavam, de algum modo, sincronizados com a música que tocava nos fones de ouvido, os casos que trazemos evocam, de uma forma ou de outra, este mesmo tipo de sensação. Por exemplo, os recursos de monitoramento de posição via GPS permitem que eventos sejam disparados toda vez que o usuário do

11 "The world again looks magnificent, much more colorful, much more varied, much freer. It is like a panorama, like a film, like a film with a story. Reality changes. One feels as if one were outside of reality. Yet one is in reality. One takes time and space much more calmly. My perception becomes richer. Space becomes richer too. Because I see the world like a play, I think, that space is the stage where one can move freely, in particular where one can play music." 
dispositivo móvel passa por um determinado ponto geográfico, possibilitam que a produção de acontecimentos evoque a sensação de que a experiência vivida, durante o trajeto, esteja sincronizada com os estímulos auditivos produzidos pelo aparelho. A sobreposição de estímulos visuais e sonoros sobre a experiência de percorrer um trecho de espaço, mesmo que familiar ao usuário, se altera completamente, visto que a duração dos eventos, por mais díspares que sejam, entram em um estado de sincronia, que é sintetizado (montado) intelectualmente pelo usuário, dando origem a uma espécie de imagem complexa e heterogênea cujos fragmentos e dimensões são compostos por distintas ordens de sensações e afetos.

O próprio gesto de caminhada, enquanto ação orientada a um fim (chegar ao trabalho, por exemplo), tem seu sentido deslocado durante um tipo de experiência como estas que relatamos a partir da pesquisa de Schönhammer (1989), em que, não raro, os depoentes sentiam que o movimento de seu corpo era ditado pelo ritmo da música. Caminhar, num contexto como este, transforma-se em um meio-termo entre deslocar-se visando uma finalidade e o gesto de dançar, que é em si uma finalidade.

No contexto de narrativas projetadas para serem acessadas e acionadas em conexão com espacialidades físicas e geográficas, observamos a emergência de outras ordens de consumo de imagens, relacionadas sobretudo aos novos significados que gestos muito simples podem assumir - como o de deslocar-se pelo território.

\section{AUDIOVISUALIDADES URBANAS}

Em Montage and architecture, Eisenstein (1989) traça um paralelo histórico e fenomenológico que conecta, genealogicamente, o espectador cinematográfico ao caminhante urbano. Para Eisenstein, assistir filmes pressupõe percorrer caminhos imaginários, que atravessam e conectam espaço-temporalidades distantes uns dos outros. O Cinema, segundo Eisenstein, herdaria da Arquitetura uma certa forma de percepção do espaço, ou seja, justamente aquela que se efetua no transcorrer de um observador que se desloca em meio a construções arquitetônicas de uma cidade, passando por diversas fachadas, alamedas, espaços fechados, abertos ou semiabertos, e, neste sentido, o caminhante urbano seria uma espécie de protótipo ancestral do espectador fílmico.

Assim, Eisenstein (1989) sinaliza, por um lado, a dimensão fílmica inerente à Arquitetura e, por outro lado, a dimensão arquitetônica presente no Cinema. Como afirma Alan Bois (1989), na introdução da referida edição de Montage and architecture, um conjunto arquitetônico é uma montagem que resulta desde o ponto de vista de um espectador em 
movimento e assim é, também, a montagem cinematográfica: “um meio de 'conectar' em um ponto no espaço - na tela - vários elementos (fragmentos) de um fenômeno filmado em várias dimensões, desde pontos de vista e ângulos diversos". ${ }^{12}$ (BOIS, 1989, p. 111, tradução nossa).

Ao evocar e analisar conformações urbanas de diferentes lugares e épocas, estabelecendo paralelos entre arquitetura e montagem fílmica, Eisenstein (1989) atualiza os rastros de um espectador fílmico em desenvolvimento. Em uma passagem, descreve a Acrópole de Atenas - que, como se sabe, abriga algumas das mais conhecidas edificações do mundo antigo - como um dos "filmes" mais antigos da história da humanidade. Erguida a 150 metros do nível do mar, a disposição dos prédios da Acrópole formava caminhos que guiavam seus visitantes através de uma sequência de vistas que poderiam ser comparadas ao processo de montagem fílmica: "uma montagem para conjuntos arquitetônicos [...] sutilmente composta, plano por plano". ${ }^{13}$ (EISENSTEIN, 1989, p. 117, tradução nossa). Imaginava Eisenstein que, ao se deslocar pela Acrópole, eram os "pés" do caminhante os responsáveis por ditar o ritmo da montagem que daria sentido ao conjunto de vistas em sequência.

Em Atlas of emotion: journeys in art, architecture and film, Giuliana Bruno (2002) comenta o ensaio de Eisenstein (1989), reforçando a ideia de que a mudança de posição do corpo no espaço se fundamenta tanto em bases arquiteturais quanto cinematográficas, visto que a relação entre filme e arquitetura envolve um processo de inscrição subjetiva de um observador que se desloca através de um campo espacial dinâmico - algo que é comum tanto ao cinema quanto à arquitetura. Para Bruno (2002, p. 56, tradução nossa), tal "observador não é um espectador estático, um olhar fixo, desencarnado. É uma entidade física, um espectador dinâmico, um corpo que realiza trajetórias no espaço" ${ }^{14}$.

Assim, uma aproximação entre Cinema e Arquitetura remeteria, segundo Bruno, a determinadas figuras de subjetividade que mesclariam propriedades psíquicas e performáticas tanto do espectador fílmico quanto de algumas das formas assumidas pelo caminhante urbano, em especial aquela que se define por seu caráter estrangeiro ao lugar visitado, ou seja, o viajante.

Quando um conjunto arquitetônico é cenicamente montado, tal como acontece frequentemente nas cidades, o efeito de visita turística é produzido. Tal efeito também é produzido pelo cinema. Os filmes criam espaços para serem vistos, examinados, atravessados. Tal como um viajante, o espectador itinerante do

12 “[...] a means to 'link' in one point-the screen-various elements (fragments) of a phenomenon filmed in diverse dimensions, from diverse points of view and sides."

13 "[...] a montage sequence for an architectural ensembles [...] subtly composed, shot by shot."

14 "Such an observer is not a stactic contemplator, a fixed gaze, a disembodied eye/I. She is a physical entity, a moving spectator, a body making journeys in space." 
conjunto fílmico-arquitetônico consome vistas em movimento como uma prática de imaginação. ${ }^{15}$ (BRUNO, 2002, p. 59, tradução nossa).

Assistir filmes é, para a autora, uma prática de habitação de um espaço, assim como se habita uma construção arquitetônica. Tal prática guarda semelhança com aquela desempenhada pelo visitante de uma cidade, quando busca alcançar diferentes ângulos e vistas para olhar a cidade: num momento o turista vai em busca de um ponto alto - uma colina, um arranha-céu, uma torre - para vislumbrar a paisagem urbana; noutro, já se encontra embrenhado com a anatomia da cidade, em suas profundezas, atravessando diferentes configurações urbanas. Tal é a dupla distância vivida na dialética entre vistas aproximadas e distantes que marcam a percepção tátil do turista em relação à cidade e à arquitetura e tal é também a multiplicidade de perspectivas - que pode ser comparada a uma montagem de vários planos em travelling que captam diversos ângulos - que também guiaria o cinema e a sua forma de visualidade: as mudanças de altura, tamanho, ângulo e escala de visão, como também de velocidade de deslocamento, fazem parte da linguagem das tomadas fílmicas, da edição e dos movimentos de câmera. É neste sentido que toda uma cultura da viagem e do turismo se desenvolve, segundo Bruno (2002), em sintonia com as bases da visualidade cinematográfica.

De modo semelhante, a tradição da pintura de vistas urbanas permite, ainda, um outro tipo de comparação entre a visualidade urbana e o espaço visual cinematográfico, que se dá na interseção entre os códigos da pintura de paisagem com os da topografia da cidade, experimentada pelo indivíduo que a explora desde o seu interior. Nas suas várias configurações e formatos, a pintura de vista foi amplamente desenvolvida pelos pintores ambulantes, que migravam de um lugar para o outro, de cidade em cidade, criando imagens do cotidiano que variavam em relação aos pontos de vista e ângulos adotados pelo pintor: desde perspectivas que enquadravam atentamente os detalhes de atividades que aconteciam no "nível da rua" até as vistas panorâmicas e aéreas que abarcavam grandes porções das cidades.

É especialmente em um quadro que mostra uma vista urbana da cidade de Toledo, pintado por El Greco, que Eisenstein (2002), em $O$ sentido do filme, perceberia um esboço de visualidade cinematográfica que se daria na junção, em simultâneo, de vistas aproximadas e distantes da cidade. Comentando o trabalho de El Greco, diz Eisenstein (2002, p. 71):

\footnotetext{
15 "When an architectural site is scenically assembled and mobilized, as cities often are, the effect of siteseeing is produced. Such traveloguing is also produced by the cinema. Film creates space for viewing, perusing, and wandering about. Acting like a voyager, the itinerant spectator of the architectural-filmic ensemble reads moving views as practices of imaging."
} 
Ele nos proporciona um exemplo do ponto de vista do artista saltando furiosamente para frente e para trás, fixando na mesma tela detalhes de uma cidade vistos não apenas a partir de vários pontos fora da cidade, mas até de várias ruas, alamedas e praças!

Assim, o amálgama de perspectivas e pontos de vista produzidos em Vista y plano de Toledo seria suficiente, segundo Eisenstein, para colocar El Greco entre os antepassados da montagem cinematográfica.

Conforme vimos até aqui, as formas de contato entre o corpo e a cidade expressam relações que a todo momento remetem a imagens e movimentos próprios de uma cultura visual forjada pelas técnicas, estéticas e imaginários cinematográficos. Canevacci (2001), em A antropologia da comunicação visual, fala sobre a expansão e reprodução dos códigos midiáticos da cultura visual baseada em imagens eletrônicas, a que ele chama de videoscape. À medida que se espalha e se enraíza em nossa cultura, o videoscape "se prolonga e se alonga nos espaços metropolitanos, configurando-os à sua imagem”. (CANEVACCI, 2001, p. 247). Assim, estaríamos vivendo hoje um momento em que os ambientes urbanos passam a assumir, cada vez mais, os traços distintivos dos videoscapes, tornando-se eles próprios parte de um grande panorama eletrônico que integra os "corpos" da cidade, dos cidadãos e das mídias num único corpo híbrido.

Nas últimas duas décadas, a acelerada expansão dos espaços navegáveis computacionais vem estabelecendo um novo conjunto de códigos midiáticos da cultura visual baseados, sobretudo, nas formas de engajamento do corpo no processo de constituição das imagens. Se Canevacci (2001) percebia na cultura visual do final do século XX uma ingerência do videoscape sobre os espaços metropolitanos, convém agora analisarmos as propriedades estéticas, narrativas e performáticas dos ambientes navegáveis computacionais imersivos e semi-imersivos, os infoscapes, tendo em vista tentar estabelecer algumas relações de contaminação entre tais espaços e os territórios urbanos.

\section{AUDIOVISUALIDADES LOCATIVAS}

No que tange às práticas narrativas site-specific aportadas pelo emprego de mídias locativas $^{16}$, diversos artistas orientam suas obras para enfatizarem os aspectos históricos e simbólicos do espaço - fazendo uso ou não de mediações tecnológicas. Para Epstein (2009), à

16 Segundo Griffis (2010), “mídias locativas" fazem referência a processos de interação social gerados a partir da articulação entre meios computacionais móveis e territórios geográficos, sejam eles para fins comerciais ou de vanguarda crítica. O uso de mídias locativas com finalidades narrativas ocorre também através de outras perspectivas, distintas das abordadas neste artigo, como, por exemplo, no trabalho de Magnoni e Miranda (2018), em que desenvolvem o enfoque jornalístico sobre este tema. 
medida que os dispositivos portáteis, com funções multimídia e de localização (GPS), se tornam mais comuns, as "narrativas terrestres", ou "terratives"17 (EPSTEIN, 2009, p. 1), começam a despontar como um gênero em si, trazendo à tona uma série de questões sobre como, na contemporaneidade, tais funções técnicas estão conduzindo à criação de experiências estéticas inusitadas. Tais modalidades narrativas encontram referência em formas culturais recentes, como também remontam a formas mais antigas, dentre as quais poderíamos citar os áudio-guias utilizados em museus e em passeios turísticos e o Teatrophone, que consistia em um sistema de transmissão à distância de performances teatrais e óperas que utilizava a rede de telefonia como meio de interação com o público. (EPSTEIN, 2009).

Assim, interessa compreender como um efeito de narrativa audiovisual pode ser produzido a partir do deslocamento do usuário de mídias móveis locativas.

$\mathrm{O}$ design de narrativas em mídias digitais se estabelece a partir do modo como os elementos de bancos de dados são arranjados em sistemas de interface e se mostram acessíveis ao acesso e à navegação dos usuários. Nos projetos de narrativas site-specific a união entre unidades de conteúdo informacional (as narrativas em áudio) e geográficas (os lugares em que o usuário deve estar posicionado para acessá-los) faz com que o princípio de modularidade das mídias digitais (MANOVICH, 2001) avance do nível técnico em direção ao cultural. Em outras palavras, em tais projetos, as narrativas sonoras se "espacializam" à medida que fragmentos modulares da(s) história(s) narrada(s) são, virtualmente, projetados sobre a arquitetura e mobiliário urbanos. Neste caso, a concepção dos bancos de dados utilizados na realização de tais projetos sugere a conexão entre elementos de naturezas materiais muito diferentes entre si: aqueles que correspondem à imaterialidade dos bits digitais e os outros que correspondem à concretude dos objetos que integram o espaço e o mobiliário urbanos.

Uma estrutura modular de narrativa pode ser encontrada em um projeto como $A$ machine to see with, referido anteriormente, em que os participantes experimentam uma narrativa no espaço urbano através de interações com ligações telefônicas via celular. Assumindo o formato de uma espécie de peça teatral participativa que utiliza o ambiente da cidade como cenário, a trama de A machine to see with se desenrola sobre um suposto assalto a banco. Todas as pessoas que desejam participar da peça devem cadastrar seu número de

17 O termo, resultante da junção das palavras territory (território) e narrative (narrativa), faz referência a modalidades narrativas que se estabelecem a partir da fusão entre territórios físicos geográficos e dados informacionais, e que demandam o uso de mídias móveis para acessá-las. (EPSTEIN, 2009). 
telefone celular, previamente, junto aos membros da equipe do Blast Theory. A partir de então, a "peça" acontece, inteiramente, via ligações de telefone para o número dos espectadores-participantes.

A "trama", conforme já dito, gira em torno de um convite a um assalto a banco. No caso de aceitar o convite, o participante passa a receber várias ligações telefônicas, através das quais são passadas orientações sobre tarefas que deve realizar e lugares aos quais deve ir, sempre com o objetivo de providenciar os preparativos para o assalto. Tal como se estivesse participando de um filme policial, suas ações são envolvidas em uma atmosfera de suspense e subversão: enquanto se locomove pelas ruas da cidade, a preocupação é não parecer suspeito; ele visita lugares abandonados; oculta seus pertences para o caso de ser capturado pela polícia; planeja os detalhes do assalto; visita o local do roubo. À medida que as tarefas vão sendo realizadas, a tensão aumenta até que o pico é atingido no momento que antecede o assalto propriamente dito.

Sem incorrermos em detalhes de como se dá o desfecho da narrativa, convém observarmos que encontramos em A machine to see with uma estrutura modular que encadeia, linearmente, os elementos narrativos, através da qual o participante vai avançando de tarefa em tarefa, ou de módulo em módulo, enquanto recebe os feedbacks telefônicos, que, além de informarem sobre seu desempenho na realização das tarefas, fornecem também elementos descritivos que ajudam a aumentar o grau de envolvimento com a história. Além disto, a peça atualiza a estrutura narrativa de vários filmes policiais de assalto a banco: no caso, o espectador-participante primeiro deve receber (e aceitar) o convite, depois planejar o assalto, para só então ir em direção ao banco em questão, momento em que o nível de tensão atinge o seu ápice, correspondendo ao clímax narrativo. Portanto, para que a experiência ocorra plenamente, esta ordem não pode ser alterada. Trata-se de uma obra que explora todo um repertório cinematográfico com o qual estamos mais do que acostumados: basta que alguns estímulos (sonoros) sejam emitidos, e todo um filme se desenrola diante de um "espectador" que caminha, apressadamente, pelas ruas da cidade.

\section{NARRATIVAS (ÁUDIO)GUIADAS}

Encontramos em A machine to see with afinidades com os trabalhos de audio walk da artista canadense Janet Cardiff ${ }^{18}$, realizados entre os anos 1990 e início dos anos 2000. As

18 Janet Cardiff é uma artista canadense, nascida em 1957, conhecida pela produção de instalações multimídia em que, frequentemente, o som desempenha papel central na experiência oferecida aos participantes de suas 
audio walks de Cardiff consistiam em peças nas quais os participantes eram convidados a caminhar por um trajeto estabelecido pela artista, que incluía o próprio ambiente urbano como cenário, enquanto escutavam, através de fones de ouvido conectados a um player de música, ${ }^{19}$ uma trilha de áudio que intercalava uma série de instruções que deveriam ser seguidas ("desça as escadas", "caminhe até o final do corredor à direita", "olhe para a janela") com fragmentos narrativos, efeitos sonoros e outros elementos. Ainda, conforme o relato de Bishop; Garrels; Weber, (1997, p. 16, tradução nossa):

\begin{abstract}
As palavras faladas e sussurradas por ela são entrecortadas com fragmentos sonoros do ambiente; pequenos excertos de áudio aparentemente gravados da TV, filmes de gênero, ou melodramas radiofônicos; e observações e questionamentos sussurrados por um homem não identificado. $\mathrm{O}$ resultado é uma colagem de áudio que toma de empréstimo elementos de fontes como os filmes noir, o cinema de vanguarda, a ficção modernista e as peças de rádio, mas que no limite não se encaixa em nenhuma categoria de prática artística. ${ }^{20}$
\end{abstract}

Segundo Cornelio (2010), apesar de não haver uso de GPS nas audio walks de Cardiff, as orientações sonoras correspondem ao deslocamento espacial do participante da experiência, provocando uma experiência de imersão intensa. Na opinião de Manovich (2006), as audio walks representam a melhor realização do paradigma de ampliação espacial, mesmo sem o uso de sofisticadas tecnologias de produção de imagens. O potencial destas peças reside, por um lado, nas interações entre os sentidos da visão e da audição, isto é, dos fluxos de contaminações sinestésicas resultantes da oscilação entre aquilo que o usuário está enxergando e os conteúdos sonoros comunicados através dos fones de ouvido; por outro lado, as peças de Cardiff provocam, ainda, o contraponto entre o presente e o passado, ou seja, entre o tempo da caminhada do usuário em contraposição ao tempo da narração, o qual, como qualquer outro tipo de gravação, pertence a algum lugar indefinido do passado. Desta maneira, Cardiff transporta a visão para além dos limites do olhar, confundindo a percepção do que é passado e do que é presente, do que se mostra como sons atuais e sons fabricados e gravados na memória do dispositivo.

Tanto nas audio walks de Janet Cardiff, quanto em uma peça performática como $A$ machine to see with, os estímulos sonoros atuam como um algoritmo performativo narrativo

obras. Ao longo da década de 1990, suas caminhadas sonoras (audio walks) renderam-lhe reconhecimento internacional. (SIMPSON, 2002).

19 Segundo Manovich (2006), a artista usava um dispositivo de discman, como eram conhecidos naquela época os players de CD portáteis.

20 "Her spoken and whispered words are intercut with bits of ambient sound; snippets of audio apparently sampled from TV, genre films, or radio melodramas; and observations or questions whispered by an unidentified man. The result is an audio collage that borrows from sources such as film noir, avant-garde cinema, modernist fiction, and radio plays but which ultimately fits into no accepted category of art making." 
que mistura o visível e o invisível, o passado e o presente, conduzindo e, ao mesmo tempo, deslocando o olhar daquele que escuta suas instruções sonoras, rememorações e fragmentos de áudio extraídos de filmes, programas de TV e de rádio. Ambos são peças performáticas, que atribuem uma certa qualidade audiovisual ao espaço percorrido sem que, no entanto, utilizem imagens (técnicas) propriamente ditas. Como afirma Cardiff sobre o seu próprio trabalho, trata-se de "disparar o efeito de um filme com apenas algumas palavras" 21 (BISHOP; GARRELS; WEBER, 1997, p. 16, tradução nossa).

A estrutura em modelo linear mostra-se como a forma mais básica de arranjo de elementos de um banco de dados, com vistas à criação de experiências narrativas, estando presente em vários tipos de produtos de mídias digitais, como na maioria dos games em que o jogador deve avançar por cada uma das fases até chegar ao término do jogo. Contudo, as estruturas modulares permitem, também, outros tipos de arranjos narrativos. Tal como observa Jeffrey Shaw (2005), uma característica apresentada pelos sistemas modulares é a possibilidade de promover trocas entre os elementos que o compõem. Assim, descreve o autor, no âmbito da produção de formatos narrativos em mídias digitais é, particularmente, comum os sistemas que apresentam "estruturas modulares de conteúdo narrativo que permitam um número indeterminado, mas significativo, de permutas”. (SHAW, 2005, p. 362). Neste sentido, as escolhas dos usuários, dentro do sistema, geram possibilidades narrativas variadas, que são tanto maiores quanto mais numerosas forem também as possibilidades de combinação entre seus elementos.

Em projetos de arte tais como $34 N 118 W$, que propõem a criação de paisagens sonoras que emergem a partir da vinculação de conteúdos de áudio a localidades urbanas, o caráter modular apresenta-se ainda mais acentuado. Em $34 N 118 \mathrm{~W}$, a proposta dos artistas Jeff Knowlton, Naomi Spellman e Jeremy Hight foi mapear, sonoramente, o espaço de um antigo distrito industrial de Los Angeles. Para tanto, os artistas produziram e geolocalizaram diversos conteúdos em áudio, os quais podiam ser acessados por usuários equipados com dispositivos móveis (no caso, laptops, fones de ouvido e navegador GPS). As narrativas contavam histórias da região, ocorridas em diferentes épocas, e misturavam contos, relatos, poemas e outros gêneros. Neste sentido, aquele que participa da experiência de exploração do referido distrito de Los Angeles depara-se com uma rede de narrativas que atuam como módulos de uma estrutura maior, ou seja, à medida que os usuários acessam os conteúdos sonoros, um quadro geral da história do lugar vai se formando, podendo variar conforme o

\footnotetext{
21 " $[\ldots]$ triggering the effect of an entire movie with just a few words."
} 
percurso realizado por cada visitante. A proposta dos artistas era criar uma experiência baseada no conceito de "arqueologia narrativa" (narrative archaeology) (HIGHT, 2006, p. 2), que se refere a um processo de "escavação" em busca de narrativas escondidas nas "camadas" cronológicas que constituem os lugares.

Desta forma, $34 N 118 \mathrm{~W}$ incentiva a exploração espacial por parte do usuário, mais do que propriamente oferecer uma experiência narrativa que se desenrola linearmente. $\mathrm{O}$ usuário é convocado a "escavar" o território em busca de fragmentos narrativos que lhe ajudem a montar um quadro geral do lugar em que a experiência toma forma.

De modo distinto, em A machine to see with (bem como nas peças de audioguia de Cardiff), o conteúdo narrativo não é propriamente mostrado ou exibido, mas é produzido, performaticamente, pelo próprio participante. Ainda que se trate de um sistema fechado, que segue uma linha narrativa predeterminada, há muito espaço para que imprevistos aconteçam: por exemplo, quando, em A machine to see with, o participante é incentivado a entrar em um banheiro público e esconder o seu dinheiro nos sapatos, o que pode acontecer se, ao chegar lá, o lugar estiver interditado ou se todas as cabines estiverem ocupadas? Neste sentido, a nosso ver, A machine to see with emprega um modelo de experiência que consegue conjugar com equilíbrio ações performáticas e o desenvolvimento narrativo.

\section{CONSIDERAÇÕES FINAIS: NOTAS SOBRE NARRATIVIDADES SONORAS SITE-SPECIFIC}

As práticas de deslocamento do corpo em espaços urbanos expressam relações que a todo momento remetem a imagens e movimentos próprios de uma cultura visual forjada pelas técnicas, estéticas e imaginários cinematográficos. Para Eisenstein (1989), o caminhante urbano, ao se deslocar em meio a construções arquitetônicas de uma cidade, passando por diversas fachadas, alamedas, monumentos, seria uma espécie de protótipo ancestral do espectador fílmico. Uma aproximação entre cinema e arquitetura remeteria, ainda, a determinadas figuras de subjetividade que mesclariam propriedades psíquicas e performáticas, tanto do espectador fílmico quanto do caminhante urbano, em especial o turista (mas também o pintor ambulante), que, em sua jornada de exploração do espaço urbano, busca alcançar diferentes ângulos de visão, ora assumindo pontos de vista elevados, ora embrenhando-se em meio à multidão.

Assim, como nas estratégias de deslocamento do corpo no espaço urbano, duas são as principais tendências de enunciação do espaço percorrido em ambientes computacionais navegáveis. A primeira tende à noção de navegação como forma de livre transitar entre 
lugares, seguindo uma lógica próxima à ideia de deriva (extensamente evocada na figura do usuário da web, que deixa-se "perder" ao navegar entre os hiperlinks da rede); por outro lado, a navegação pode ser orientada de modo que o espaço percorrido produza um efeito de narrativa (tal como acontece em muitos games).

À medida que se tornam mais comuns os sistemas de bancos de dados, o princípio de modularidade (MANOVICH, 2001), que pauta o funcionamento das mídias digitais, extrapola o domínio dos universos "puramente" computacionais e se irradia para outras áreas da cultura, autorizando o surgimento de estéticas de conectividades híbridas que combinam elementos digitais e analógicos tal como observamos nos projetos artísticos com mídias locativas. Seguindo nesta direção, ao longo deste texto, propusemos a análise de alguns casos de narrativas site-specific, as quais foram discutidas desde a perspectiva das formas de enunciação que produzem quando viabilizadas pelo corpo em movimento de usuários de dispositivos móveis.

Conforme vínhamos observando, também no âmbito dos usos criativos com mídias locativas, os projetos que estimulam o deslocamento do corpo no espaço parecem conjugar tanto propostas de exploração espacial quanto também de experiências narrativas. De todo modo, o que está em jogo é o tipo de algoritmo performativo que orienta a performance do corpo em sintonia com o aparato tecnológico.

Observamos que efeitos narrativos surgem da sincronização entre estímulos audiovisuais (imagéticos, sonoros, textuais) e o posicionamento espacial dos participantes. Em cada caso, o princípio de modularidade pode dar origem a diferentes tipos de configuração da estrutura narrativa: em A machine to see with, a estrutura narrativa apresentase linearmente, de modo que o participante deva seguir módulo por módulo (ou cena por cena) até o final da história; em projetos como $34 N 118 \mathrm{~W}$, o caráter modular mostra-se mais acentuado, de modo que não há uma ordem prévia a ser seguida em relação ao acesso dos conteúdos vinculados ao espaço territorial.

Ainda, em $34 N 118 \mathrm{~W}$ a dinâmica de interação com os conteúdos geolocalizados estimula o usuário a "escavar" o território em busca de fragmentos narrativos. Tal "escavação" é sempre atrás de rastros, lembranças e rememorações de acontecimentos relatos pessoais, mensagens, cenas ficcionais, imagens, não importa, é sempre como um comentário sobre o passado que tais conteúdos chegam à superfície das telas dos dispositivos móveis usados para recuperá-los. Por fim, em A machine to see with (bem como nas peças de audio walk de Janet Cardiff), o “algoritmo" estimula a ação sempre em tempo presente, 
incitando o participante a engajar-se, performativamente, nos acontecimentos narrados, tornando-se, deste modo, o centro ao redor do qual a trama se desenvolve.

Em conclusão, consideramos que, ironicamente, projetos baseados fundamentalmente na audição parecem alcançar maior êxito no que se refere aos processos de atualização de virtualidades audiovisuais em experiências de deslocamento do corpo pelo território urbano. Tanto A machine to see with como as peças de Cardiff são experiências de deslocamento do corpo no espaço que se mostram capazes de evocar, através de rastros, fragmentos e vestígios, todo um imaginário audiovisual que se hibridiza às ações do corpo em deslocamento pela cidade - algo que nos remete, diretamente, aos depoimentos dos voluntários que participaram do estudo sobre o hábito de escutar músicas em aparelhos do tipo Walkman, comentado anteriormente.

Cabe ainda destacar, uma vez mais, que, conforme referimos na introdução deste texto, o audiovisual se estabelece, hoje, mais do que nunca, como um fundo sobre o qual a visualidade contemporânea toma forma. A consequência radical deste processo é que, passados mais de cem anos da invenção do cinema, nossa cultura encontra-se em um estágio tão avançado de assimilação dos códigos audiovisuais, que, hoje em dia, as imagens não precisam mais sequer se apresentar como "imagens" para serem percebidas como tais. Como diria Janet Cardiff, para deflagrarmos um efeito cinematográfico, bastam apenas algumas palavras.

Neste momento, também retomamos o comentário de um dos participantes dos estudos sobre as práticas de escuta musical em aparelhos portáteis (do tipo Walkman) que comentávamos anteriormente. Conforme dizia, ao andar pela cidade escutando música através dos fones de ouvido, o mundo se transformava em um filme e os acontecimentos da vida cotidiana pareciam ser controlados pelo ritmo da canção. Mais do que nunca a questão colocada por Dubois (2004, p. 12) faz sentido: “Quem, ao percorrer de carro um longo trajeto numa vasta paisagem aberta, não pensou, com a ajuda da música no rádio, numa figura de travelling mergulhando na tela panorâmica de seu para-brisa?”.

\section{REFERÊNCIAS}

34 NORTH 118 WEST. In: 34 North 118 West, [S. l.], 2003. Disponível em: https://34n118w.net/34N/. Acesso em: 10 out. 2020.

34N118W. In: 34 North 118 West, [S. l.], 2003. Disponível em: http://34n118w.net/34N/jpgs/IM01.jpg. Acesso em: 10 out. 2020. 
BISHOP, Janet; GARRELS, Gary; WEBER, John (org.). Present tense: nine artists in the nineties. San Francisco: San Francisco Museum of Modern Art (SFMOMA), 1997.

BOIS, Yve-Alain. Introduction. In: EISENSTEIN, Sergei. Montage and architecture. Assemblage. The MIT Press, Cambridge, Dec. 1989, n. 10, p. 111-131.

BOLTER, David; GRUSIN, Richard. Remediation: understanding new media. Cambridge: MIT Press, 2000.

BRUNO, Giuliana. Atlas of emotion - journeys in art, architecture, and film. Nova York: Verso, 2002.

CANEVACCI, Massimo. Antropologia da comunicação visual. Rio de Janeiro: DP\&A Editora, 2001.

CORNELIO, Gemma. Mapas, teléfonos móviles y narraciones: possibilidades y estado de lacuestión de los locative media. Anàlisi, Barcelona, 2010. Quaderns de Comunicació i Cultura, n. 40, p. 115-128.

DUBOIS, Philippe. Cinema, vídeo, Godard. São Paulo: Cosac Naify, 2004.

EISENSTEIN, Sergei. Montage and architecture. Assemblage. The MIT Press, Cambridge, Dec. 1989, n. 10, p. 111-131.

EISENSTEIN, Sergei. O sentido do filme. Rio de Janeiro: Jorge Zahar, 2002.

EPSTEIN, Michael. Moving Store. Media in transition 6: stone and papyrus, storage and transmission. Cambridge: MIT, 2009.

FELINTO, Erick. Um futuro complexo, híbrido, incerto e heterogêneo. [Entrevista cedida a] Márcia Junges e Thamiris Magalhães. IHU-Online: revista do Instituto Humanitas Unisinos, São Leopoldo, ed. 375, 3 out. 2011.

GRIFFIS, Ryan. Por uma arte contra a cartografia da vida cotidiana. In: Mediações, tecnologia e espaço público: panorama crítico da arte em mídias móveis. BAMBOZZI, Lucas; BASTOS, Marcus; MINELLI, Rodrigo (org.). São Paulo: Conrad Editora do Brasil, 2010 .

HIGHT, Jeremy. Views from above: locative narrative and the landscape. Leonardo Electronic Almanac, Studio City, Nov. 2006, v. 14, n. 7-8, p. 1-10, 2006.

HUHTAMO, E.; PARIKKA, Jussi. Media archeology: approaches, applications, and implications. Berkeley, California: University of California Press, 2011.

JENKINS, Henry. Game design as narrative architecture. In: WARDRIP-FRUIN, Noah; HARRIGAN, Pat (org.). First Person: new media as story, performance, and game.

Cambridge: MIT Press, 2004. 
KILPP, Suzana. Audiovisualidades de TV: apontamentos preliminares sobre imagemduração. Contemporânea - Revista de Comunicação e Cultura, Universidade Federal da Bahia, Ondina, v. 4, n. 1, p. 1-18, 2006.

LEMOS, André. Mídia locativa e territórios informacionais. In: ARANTES, Priscila; SANTAELLA, Lúcia (org.). Estéticas tecnológicas. São Paulo: PUC, 2007.

LOPES, Tiago. A aura e os vestígios do audiovisual em experiências estéticas com mídias locativas: performances algorítmicas do corpo no espaço urbano. Tese (Doutorado em Comunicação - Universidade do Vale do Rio dos Sinos, São Leopoldo, RS, 2014. Disponível em: http://biblioteca.asav.org.br/vinculos/000012/00001222.pdf. Acesso em: 10 out. 2020.

MAGNONI, A. F.; MIRANDA, G. V. Jornalismo hiperlocal e internet: a comunicação hiperlocal cidadã como possibilidade na arena pública. Comunicação \& Informação, Goiânia, v. 21, n. 3, p. 166-184, 2018.

MANOVICH, Lev. Poetics of augmented space. Visual Communication, Londres, Sage Publications, v. 5, n. 2, p. 219-240, 2006.

MANOVICH, Lev. The language of new media. Massachusetts: The MIT Press, 2001.

SANTAELA, Lucia. Linguagens líquidas na era da mobilidade. São Paulo: Paulus, 2007.

SCHÖNHAMMER, Rainer. The Walkman and the primary world of the senses.

Phenomenology + Pedagogy, [S. l.], v. 7, p. 127-144, 1989.

SHAW, Jeffrey. O cinema digitalmente expandido: o cinema depois do filme. In: LEÃO, Lúcia (org.). O chip e o caleidoscópio: reflexões sobre as novas mídias. São Paulo: Senac, 2005.

SIMPSON, Bennett. Walk on By - Janett Cardiff. Frieze, [S. l.], 4 Apr. 2002. Disponível em: https://www.frieze.com/article/walk. Acesso em: 10 out. 2020.

TUTERS, Mark; VARNELIS, Kazys. Beyond locative media: giving shape to the Internet of things. Leonardo, [S. l.], v. 39, n. 4, p. 357-326, 2006. 